\title{
Daylight Design Strategies: A Lesson from Iranian Traditional Houses
}

\author{
Faezeh Nabavi \\ Department of Architecture, Faculty of Built Environment, \\ University of Malaya, Malaysia \\ Yahaya Ahmad \\ Department of Architecture, Faculty of Built Environment, \\ University of Malaya, Malaysia
}

Ai Tee Goh

Principal, A T GOH Architect, Malaysia

\section{Doi:10.5901/mjss.2013.v4n9p97}

\begin{abstract}
Iranian traditional houses had shown an intimate connection with nature, responsive to climate and occupant's requirement. A great aspect of these houses is its adaption to the special climate (Hot and Arid) of the most parts of the country, while, most of the modern houses nowadays have lost this link. In Iran, courtyard houses is the most prominent house type in Hot- Arid region and physical feature of it reflects natural needs and environment responding. This paper aims to focus on quality of daylighting in these houses, which can sign impact on personal emotional needs of well- being. This study analyzed the application of the building elements and solutions to bring daylight into different parts of these traditional courtyard houses. Twenty selected traditional houses in this region were examined. The analysis includes accessing the quality of space within these houses in term of form, opening and shady elements. This paper has concluded with daylight design strategies ascertain from the analysis of these traditional houses that may be adopted in modern house design in Iran and enhance the quality of their design.
\end{abstract}

Keywords: Traditional House, Courtyard, Daylight, Hot- Arid region

\section{Introduction}

Light and life go hand-in-hand. Our perception of space is dependent upon light; it is not possible to gauge spatial relationships with the lack of light. Light is capable of changing the quality of space and phenomenon. It illuminates objects, and shadows casted from light change the monotony of space, contrasting our mental picture. Nothing is more conducive to a healthy and pleasant house than adequate sunlight.

The traditional architecture of Iran has been a subject of scrutiny for decades, and via such researches, many mysterious tricks are discovered, with architects utilizing them to create meaningful spaces (Arjmandi, Tahir, \& Shabani, 2010). Besides its functional aspect, day lighting was important in traditional architecture, due to its spiritual and decorative aspects. Day lighting was integrated with other elements of architecture, and remains inseparable from it.

In the Hot- Arid region of Iran, lower levels of humidity and the lack of clouds results in extreme temperature fluctuations during both day and night (Iranmanesh \& Bigdeli, 2009). This phenomenon prompted designers and architects to use natural climatic approaches in order to adapt to these harsh conditions(Taleghani, Behboud, \& Heidari). Thus, in this region, more than a few architectonic elements, with those illustrating various strategies, have been developed with major environmental and cultural potentials.

The majorities of traditional houses are introverted, or look inwards. All the spaces were arranged around an open, rectangular courtyard that links the different areas of the house. The arrangement follows certain geometrical configuration. This paper aims to examine the factors and spaces in traditional Iranian houses, related to daylight. 


\section{Methodology}

In order to analyze the criteria of traditional houses, the researcher used multiple case studies (Yin, 2009) and examined twenty traditional houses located in different cities of the Hot- Arid region. Based on the data from the Cultural Heritage Organization in Iran, twenty traditional houses that are still in good condition were selected. Other selection criteria for case studies include are; all these houses must registered with the Cultural Heritage Organization in Iran; they were all built between 1850- 1880 AD (Qajarian era - the prominent point in the architecture of this era was housing, so these samples are the best samples in Iran); and located in the Hot- Arid region. Field trips to these twenty selected traditional houses were carried out by the primary author in year 2012 (August- November). With a set of checklist, nonparticipation observation and systematic photography record were collected during the field trips.

\section{Hot- Arid region of Iran}

In different regions of the world, due to its climate, will employs its own construction techniques, materials, and designs in its respective buildings (Moosavi, 2011). The Hot-Arid region encompasses the majority of the central Iranian plateau (Daniel, 2006)(see figure1). Summer is very hot and arid, while winter is very cold, with less rain and snow. The sky, for the most part of the year, remains cloudless, while the temperature fluctuates greatly in this area (Kasmaei, 2003; Qobadian, 2006). Due to these climate factors, the builders should provide logical solutions to ensure comfort (Soflaee, 2005).

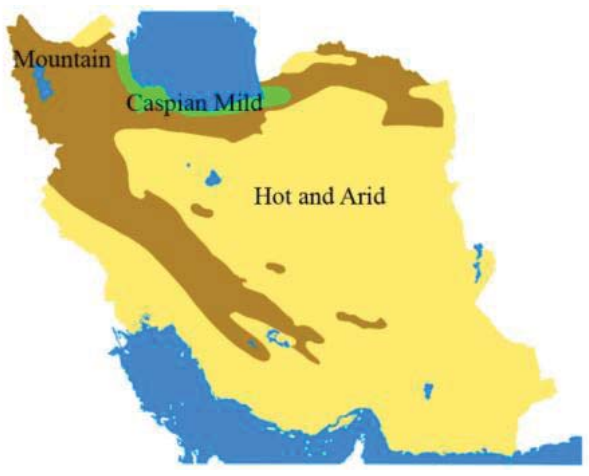

\section{Traditional Houses}

Houses in traditional architecture of Iran were all based on special principles, which still remain in practice today (Pirnia, 2005). All of these buildings were built in order to fulfill people's requirements (Arjmandi et al., 2010). It emphasizes the relationship between the building and the user (Shabani, Tahir, Shabankareh, Arjmandi, \& Mazaheri, 2011). The physical features of traditional Iranian houses reflect natural, cultural needs and the occupant's requirements (Mirmoghtadaee, 2009).

\section{Building Orientation}

Topography is a necessary parameter that determines the architecture of the hot and arid area in Iran. In this region, traditional buildings are molded according to the slope of a hill of the city; and due to the sun, wind and weather, they are oriented in two distinct directions. Owing to the characteristics of sun and wind in this region, the North East- South west and North West-South East (see figure2) are suitable position for orientation in order to maximize summer and winter room's usage, as well as service rooms at the east façade (receiving west daylight) acting as a buffer zone for the heat (Pirnia, 2005; Qobadian, 2006). 

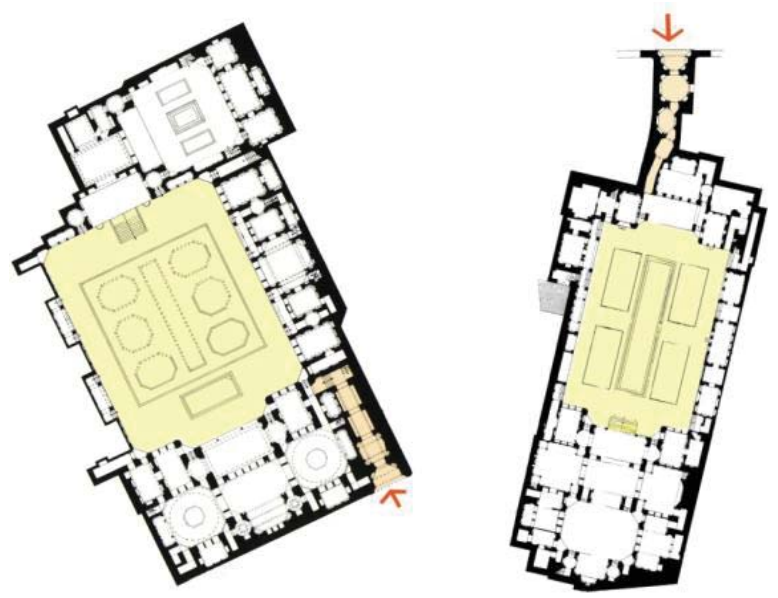

\section{Building Form}

Most of the traditional houses in Iran are known to have a courtyard (see figure2). Literature reviews suggest that courtyards house type are an environmentally responsive building form for Hot- Arid climates (Ratti, Raydan, \& Steemers, 2003). These houses are common in Hot-Arid climates, and remain standing in many historical regions in the Middle East (Bekleyen \& Dalkiliç, 2011). In Iran, courtyard houses are the most prominent type of house (Moradi \& Akhtarkavan, 2008). In addition to climatic factors, this form fulfills several functions in the Hot-Arid region (Bahadori, 1978; Fathy, 1986; Ratti et al., 2003). It usually functions as a heart of the house in the spatial, social and environmental context. A courtyard can provide security, privacy and comfort within a home. The inward-looking courtyard and the various configurations of windows constitute the day lighting channels in these houses (Belakehal, Tabet Aoul, \& Bennadji, 2004). The idea of a garden and a courtyard complements the hot and arid plateau of Iran (see figure3), and remains as significant representation of the concept of paradise during the Islamic era (Ardalan, Bakhtiar, \& Nasr, 1973).
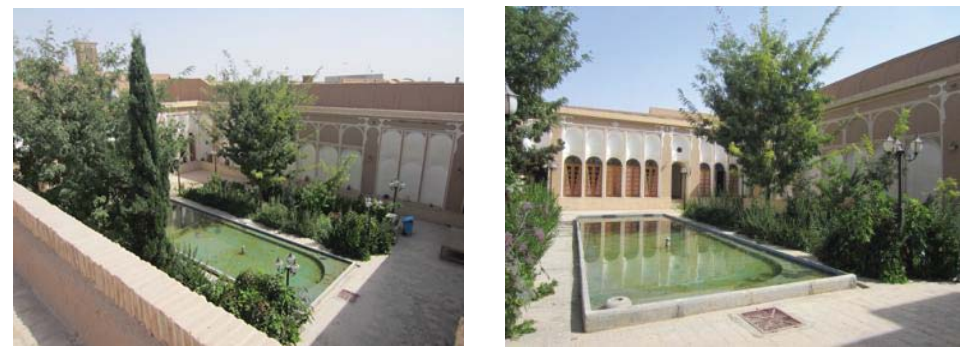

\section{Daylight design strategies of traditional houses}

Natural light is the primary source of lighting in a building, due to the lower costs and its permanent status. Different spaces in traditional houses have unique response towards daylight (Arjmandi et al., 2010).

\section{Daylight elements in traditional houses}

There are different daylight elements in traditional houses, which play a vital role in transferring daylight to the other spaces in the house. 


\section{Courtyard}

The courtyard model provided various functions for the residents and its users. Many scholars in Iran have displayed this model as an appropriate solution to the functional, climatic, social and cultural needs of the Iranian people. Climatically, courtyards acted as efficient micro-climate controllers and important element to distribute daylight, as all of the rooms and spaces surrounds the courtyard (Bahadori, 1978) (see figure3).

The pool inside the courtyard is a transparent element, which plays an important role in light reflection and passing the light to the internal layers of the house (Arjmandi et al., 2010).

\section{Iwan}

Iwan, or semi-open areas, are used to provide a shade and cool living spaces during the day (Pirnia, 2005). The Iwan is a closed passageway in front of the rooms that permits a common life inside (an open living room inside the house). They are usually oriented to the south. It is also noted that south and east-oriented Iwans are very cool, and provide shady spots during the sweltering heat of the summer afternoons (Nabavi, Yahaya, \& Goh, 2012)(see figure4).

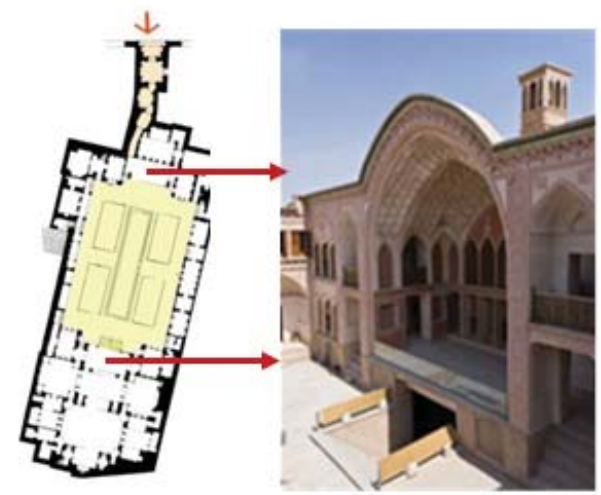

\section{Shape and type of the opening}

Each opening in a traditional house consists of many details that play an important role in optimizing daylight (see figure5).

\subsection{Tabesh Band}

It is an edge around the window that functions as a canopy. It could also be a tore with a different size. It is usually placed on the window in the room, designated for either winter or summer (Pirnia, 2005).

\subsection{Lattice Frame}

These frames are beautiful wooden frames with unique motifs, which control day light, especially intense rays of the sun in the hot summer (Qobadian, 2006). 

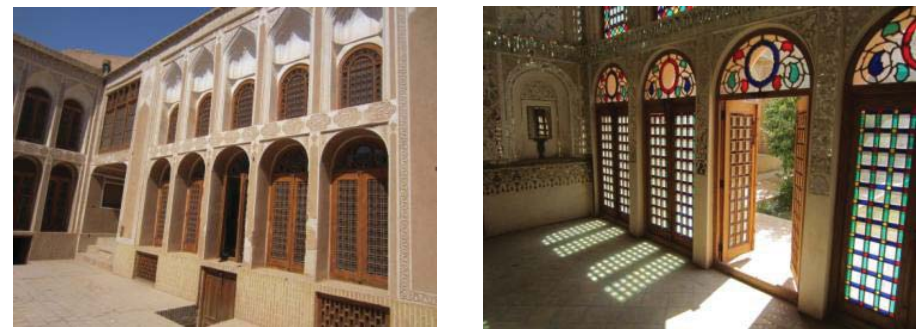

\subsection{Colorful Glass}

Colorful glass controls the light and creates beautiful patterns in the rooms. It is not difficult to imagine the great ambience made by rays of light, poured through the stained glass windows, in the rooms. Some special colors function as insect repellants during the hot summer days (Nabavi et al., 2012)(see figure5).

\section{Daylight sequences (spatial arrangement)}

The spatial arrangement was collecting different spaces near each other and around the courtyard to allow light to pass by a specific sequence. After passing the courtyard as an open space, they were semi- open spaces, and their functions were semi- public. These spaces were unrestricted to open spaces, and blocked by a closed space.

In most traditional houses, in terms of lighting, the indoor area is divided into three layers. The primary layer is the one that is closed to the openings, and receives daylight from the central courtyard in a straight line. This space has the most potential in passing light to other spaces. The second layer, which is shown to be darker, is the area that gets the light from the first part, and uses natural daylight as well (Arjmandi et al., 2010). This space works as a mediating space for the purpose of light sharing. The last layer is the one that receives the light from the intermediate area, or from the small apertures on the ceiling.

There is a daylight sequence in entering part of a traditional house as well. The first and important principle in designing the entrance is hierarchy. In a traditional house in Iran, the main entrance was made up of a vestibule (Hashti); a small enclosed traditional space that one steps into after entering the doorway. It is a decorated space with skylight, and without any windows. After this part, there are indirect corridors, which usually do not have any holes in the ceiling. After passing a corridor, the courtyard acts as a spot light inside the house (Tavassoli, 2002). The play with both shadow and light in this sequence creates a sense and meaning for the space.

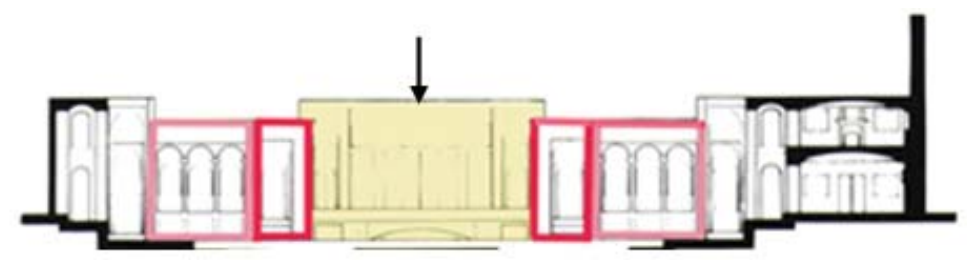

\section{Result and Discussion}

After analyzing twenty traditional houses in the Hot-Arid region of Iran, most of the daylight strategies are confirmed. The results are shown in the table 1. By and large, these strategies area as follows:

i. All of the houses follow the rule of orientation, which are North East- South west, or North West- South

ii. All of these houses possess an inner rectangular courtyard and other spaces surrounding the yard. There is a pool inside the courtyard, with trees and other plants.

iii. There is an entering sequence in all of these traditional houses (Bright space, semi- bright, dark and spotlight). Only in few cases, due to the land size, vestibules are absent.

iv. All the openings abide by the aforementioned rules, which are beautiful lattice wooden frame, with colorful glasses decorating the façade surrounding the courtyard. 
v. The layering of spaces is designed correctly, and abides by the rule for bringing light into inner spaces of traditional house.

\begin{tabular}{|c|l|c|c|c|c|}
\hline NO & \multicolumn{1}{|c|}{ NAME } & $\begin{array}{c}\text { Orientation } \\
\text { (North East-South West or NE-SW) } \\
\text { (North West-South East or NW-SE) }\end{array}$ & $\begin{array}{c}\text { Form } \\
- \text { Inner } \\
\text { Courtyard } \\
\text { with Pool }\end{array}$ & $\begin{array}{c}\text { Entering } \\
\text { Sequence }\end{array}$ & $\begin{array}{c}\text { Opening- } \\
\text { with Lattice } \\
\text { frame and } \\
\text { colorful glasses }\end{array}$ \\
\hline 1 & Akhavan & NE-SW & $\checkmark$ & $\checkmark$ & $\checkmark$ \\
\hline 2 & Al- e- Yasin & NE-SW & $\checkmark$ & $\checkmark$ & $\checkmark$ \\
\hline 3 & Arab- Alireza & NE-SW & $\checkmark$ & $\checkmark$ & $\checkmark$ \\
\hline 4 & Arab- Bibi roqayeh & NE-SW & $\checkmark$ & $\checkmark$ & $\checkmark$ \\
\hline 5 & Ardakanian & NE-SW & $\checkmark$ & $\checkmark$ & $\checkmark$ \\
\hline 6 & Bakuchi & NW-SE & $\checkmark$ & $\checkmark$ & $\checkmark$ \\
\hline 7 & Boroujerdi-ha & NE-SW & $\checkmark$ & $\checkmark$ & $\checkmark$ \\
\hline 8 & Esfehanian & NE-SW & $\checkmark$ & $\checkmark$ & $\checkmark$ \\
\hline 9 & Farhangi & NE-SW & $\checkmark$ & $\checkmark$ & $\checkmark$ \\
\hline 10 & Fateh- ha & NW-SE & $\checkmark$ & $\checkmark$ & $\checkmark$ \\
\hline 11 & Lari- ha & NE-SW & $\checkmark$ & $\checkmark$ & $\checkmark$ \\
\hline 12 & Malek- zadeh & NE-SW & $\checkmark$ & $\checkmark$ & $\checkmark$ \\
\hline 13 & Mahmoodi & NE-SW & $\checkmark$ & $\checkmark$ & $\checkmark$ \\
\hline 14 & Mashrouteh & NE-SW & $\checkmark$ & $\checkmark$ & $\checkmark$ \\
\hline 15 & Meshkian & NE-SW & $\checkmark$ & $\checkmark$ & $\checkmark$ \\
\hline 16 & Mortaz & NE-SW & $\checkmark$ & $\checkmark$ & $\checkmark$ \\
\hline 17 & Mozaffari & NE-SW & $\checkmark$ & $\checkmark$ & $\checkmark$ \\
\hline 18 & Olumi- ha & NW-SE & $\checkmark$ & $\checkmark$ & $\checkmark$ \\
\hline 19 & Rasoolian & NE-SW & $\checkmark$ & $\checkmark$ & $\checkmark$ \\
\hline 20 & Tabataba' ee & NW-SE & & & \\
\hline
\end{tabular}

\section{Conclusion}

As it can be concluded from the consequences of the case study, there are many different ways for bringing daylight into the house. As far as the importance of natural light in human's life is concerned; there have been severe attempts in architecture for bringing in daylight. The traditional architecture of Iran is enriched by various openings, apertures and meaningfulness of the space, admitting daylight from more than one side of a space where possible.

Most of these daylight design strategies are useful in contemporary houses design, which have unfortunately been largely forgotten. Consequently, consideration and development of the aforementioned strategies highlighted in this paper allows contemporary architects and designers to build modern architecture in a more sustainable, comfortable and self-sufficient way.

\section{References}

Ardalan, N., Bakhtiar, L., \& Nasr, S. H. (1973). The sense of unity: the Sufi tradition in Persian architecture: University of Chicago press Chicago.

Arjmandi, H., Tahir, M., \& Shabani, M. (2010). Application Of Transparency To Increase Day Lighting Level Of Interior Spaces In The Dwelling Apartments In Tehran-A Lesson From Iranian Traditional Architecture. Editorial Board/Sidang Editor.

Bahadori, M. (1978). Passive cooling systems in Iranian architecture. Sci. Am.;(United States), 238(2).

Bekleyen, A., \& Dalkiliç, N. (2011). The influence of climate and privacy on indigenous courtyard houses in Diyarbakır, Turkey. Scientific Research and Essays, 6(4), 908-922.

Belakehal, A., Tabet Aoul, K., \& Bennadji, A. (2004). Sunlighting and daylighting strategies in the traditional urban spaces and buildings of the hot arid regions. Renewable energy, 29(5), 687-702.

Daniel, E. L. (2006). Culture and customs of Iran: Greenwood Press.

Fathy, H. (1986). Natural energy and vernacular architecture.

Iranmanesh, N., \& Bigdeli, E. (2009). Climatic design \& low carbon city regarding the traditional, experiences Climatic design \& low carbon city. Paper presented at the 45th ISOCARP Congress.

Kasmaei, M. (2003). Climate and architecture. Soil publication, Esfahan., Iran.

Mirmoghtadaee, M. (2009). Process of Housing Transformation in Iran. Journal of Construction in Developing Countries, 14(1), 69-80.

Moosavi, M. (2011). An Analysis to Historic Roots of Climatic Design in Ancient Architecture of Central Zone of Iran. 2nd International 
Conference on Humanities, Historical and Social Sciences, IACSIT Press, Singapore vol.17.

Moradi, A. M., \& Akhtarkavan, M. (2008). Sustainable architecture in the hot, arid and sunny regions of Iran. Architect Engineering Special Issue, 19(6), 21-29.

Nabavi, F., Yahaya, A., \& Goh, A. T. (2012). Daylight and Opening in Traditional Houses in Yazd, Iran. http://www.plea2012.pe/pdfs/T08-20120129-0036.pdf

Pirnia, M. K. (2005). Introduction to Islamic Architecture in Iran (Vol. 10). Tehran, Iran: Soroosh Danesh.

Qobadian, V. (2006). A Survey on the Climatic design of the Iranian traditional buildings. Tehran University, Tehran.

Ratti, C., Raydan, D., \& Steemers, K. (2003). Building form and environmental performance: archetypes, analysis and an arid climate. Energy and Buildings, 35(1), 49-59.

Shabani, M. M., Tahir, M. M., Shabankareh, H., Arjmandi, H., \& Mazaheri, F. (2011). Relation of cultural and social attributes in dwelling, responding to privacy in Iranian Traditional House. e-BANGI: Jurnal Sains Sosial dan Kemanusiaan, 6(2), 273-287.

Soflaee, F. (2005). Environmental Analyzes of Courtyard in the Sustainable Architecture of Hot-Aired Region. Paper presented at the Printed in Proceeding of International Conference of Kerpic Network,(ITU, Turkey, Istanbul.

Taleghani, M., Behboud, K. T., \& Heidari, S. ENERGY EFFICIENT ARCHITECTURAL DESIGN STRATEGIES IN HOT-DRY AREA OF IRAN: KASHAN.

Tavassoli, M. (2002). Urban structure and architecture in the hot arid zone of Iran. Tehran/Iran.

Yin, R. K. (2009). Case study research: Design and methods (Vol. 5): SAGE Publications, Incorporated

\section{Picture's references}

Figure1:I.R of IRAN meteorological organization Figure2, 6: Cultural Heritage Organization of Iran Figure3, 4, 5: The author 